\title{
OPEN The adsorptive behaviour of kaolinite to sodium dodecyl benzene sulphonate and the structural variation of kaolinite
}

\begin{abstract}
Xiaoming $\mathrm{Ni}^{1,2}$, Zheng Zhao ${ }^{1 凶}$, Zhiheng $\mathrm{Li}^{3}$ \& Quanzhong Li ${ }^{2}$
Analysis of the adsorptive behaviour of kaolinite to sodium dodecyl benzene sulphonate (SDBS) at different concentrations can provides a basis for selecting the best concentration. The adsorptive capacity and adsorptive behaviour of kaolinite to SDBS at different concentrations were studied using ultraviolet spectrophotometer, pseudo-first-order adsorption kinetics model, and pseudosecond-order adsorption kinetics model. Scanning electron microscopy with energy dispersive spectrometry (SEM-EDS), X-ray diffraction (XRD), and infrared spectroscopy (FTIR) were used to study the variation characteristics of surface structure, crystallinity indices, and main functional groups on kaolinite before, and after, adsorption. The results show that as the SDBS concentration increase, the adsorptive capacity of kaolinite to SDBS increase. The adsorption process can be accurately fitted by the pseudo-secondary adsorption kinetic model, which means the adsorptive behaviour was mainly chemical in origin. The adsorption of SDBS by kaolinite mainly occurs on the surface. The solidification, lamellar aggregation, and crystallinity index of kaolinite are more obvious after the adsorption of SDBS, but the interlayer spacing of kaolinite did not change to any significant. After the adsorption of SDBS, the intensity ratio of $1000-1008 \mathrm{~cm}^{-1}$ bands changed significantly, indicating the change of the chemical environment, and the adsorptive behaviour was chemical.
\end{abstract}

Coal rocks, sandstone and shale reservoirs often contain clay minerals such as kaolinite. When hydraulic fracturing is carried out on these reservoirs, clay minerals and fracturing fluids in the reservoirs are prone to produce effects such as velocity sensitivity, alkali sensitivity and salt sensitivity, which have a great impact on the effect of reservoir reconstruction. After adding surfactant to the fracturing fluid, surface active agents are often adsorbed on clay minerals ${ }^{1-4}$ to change the surface structure of clay minerals and reduce the above effects. Sodium dodecyl benzene sulphonate (SDBS) is a commonly used anionic surfactant ${ }^{5}$, discovering the adsorption characteristics of SDBS on the surface of kaolinite minerals can provide a basis for the selection of the optimum concentration thereof.

The adsorptive behaviour of solids to surfactants can be described by fitting the adsorption process at different times using classical models. Among them, the methods for measuring the adsorptive capacity are mainly spectrophotometric and liquid chromatographic techniques. The spectrophotometric measurement method involves supernatant being collected from centrifuged liquid for measurement of absorbance. Then the adsorptive capacity is obtained according to the relationships between concentration and absorbance. This method, due to its ease of operation, is a common method used for testing the adsorptive capacity ${ }^{6,7}$. Liquid chromatography is based on the small differences in physical and chemical properties with regard to the solubility, adsorptive capacity, and ion exchange capacity of substances. These should be combined with the differences between the partition coefficient of mobile and fixed phases: the various substances to be measured were separated through the distribution of their fixed and mobile phases, according to the difference in relative solubility between both phases $^{8,9}$. The adsorptive capacity (for quantitative evaluation) also requires spectrophotometry. The commonly adsorption kinetic models used in fitting adsorption processes include the pseudo-first-order adsorption kinetic

${ }^{1}$ School of Energy Science and Engineering, Henan Polytechnic University, Jiaozuo 454000, China. ${ }^{2}$ Mining Engineering Department, Shanxi Institute of Technology, Yangquan 045000, China. ${ }^{3}$ China Coal Technology Engineering Group Chongqing Research Institute, Chongqing 400037, China. ${ }^{\circledR}$ email: 18839137273@163.com 


\begin{tabular}{|l|l|l|l|l|l|l|l|l|l|l|}
\hline Mineral & Component & $\mathrm{Al}_{2} \mathrm{O}_{3}$ & $\mathrm{SiO}_{2}$ & $\mathrm{Fe}_{2} \mathrm{O}_{3}$ & $\mathrm{TiO}_{2}$ & $\mathbf{M g O}$ & $\mathrm{CaO}$ & $\mathrm{Na}_{2} \mathbf{O}$ & $\mathrm{K}_{2} \mathrm{O}$ & Others \\
\hline Kaolinite & Mass fraction (\%) & 39.2 & 43.67 & 0.32 & 1.98 & 0.068 & 0.01 & 0.028 & 0.094 & 14.63 \\
\hline
\end{tabular}

Table 1. The oxidic composition of kaolinite.

model, pseudo-second-order adsorption kinetic model, Elovich kinetic model, and Bangham adsorption rate model ${ }^{10-15}$. It is generally believed that pseudo-first-order adsorption kinetics model is more accurate for the adsorption process fitting of physical adsorption, while the pseudo-second-order adsorption kinetics model is more accurate when simulating chemical adsorption ${ }^{16-18}$. The structural change characteristics of minerals after adsorption of anionic surfactant were mainly detected by scanning electron microscopy with energy dispersive spectrometry (SEM-EDS), X-ray diffraction (XRD), and infrared spectroscopy (FTIR) ${ }^{19-24}$.

Herein, the adsorptive capacity of kaolinite to SDBS at different concentrations under different time was tested with the help of ultraviolet spectrophotometry, and the adsorption type of SDBS was determined by fitting the adsorption process with the classical model. SEM-EDS, XRD, and FTIR were used to test the differences in element content, layer spacing, and main functional groups before and after adsorption. The structural changes of kaolinite were thus obtained. The research can provide a basis for selecting the best concentration of SDBS.

\section{Experimental samples}

The main samples required for the experiment were the anionic surfactant SDBS and kaolinite minerals. The SDBS (analytically pure) used in the experiment was produced by Fangzheng Reagent Factory, Beichen District, Tianjin, China. In the SDBS $\left(\mathrm{C}_{18} \mathrm{H}_{29} \mathrm{NaO}_{3} \mathrm{~S}\right)$, the active substance content is $\geq 90 \%$, the sodium salt content is $\leq 7 \%$, and the moisture content is $\leq 3 \%$. The block sample had good crystallinity and few impurities (the kaolinite content is greater than $95 \%)$. The kaolinite sample was pulverised and then tested by X-ray diffraction and energy spectral analysis. The chemical formula of the kaolinite powder was $\mathrm{Al}_{2} \mathrm{Si}_{2} \mathrm{O}_{5}(\mathrm{OH})_{4}$. The oxidic composition and mass fraction of each mineral in kaolinite are shown in Table 1.

\section{Research methods The adsorptive behaviour of kaolinite to SDBS.}

(1) The test for adsorptive capacity.

1. Sample preparation

We weighed $2.000 \mathrm{~g}$ of kaolinite (three pieces) on a precision balance and placed them into a conical bottle. $200 \mathrm{~mL}$ of SDBS solutions with concentrations of $3 \mathrm{mmol} / \mathrm{L}, 4 \mathrm{mmol} / \mathrm{L}$, and $5 \mathrm{mmol} / \mathrm{L}$ were thus prepared.

2. Absorbance test

The three different concentrations of SDBS solutions were poured into the conical flask containing kaolinite and then stirred on a magnetic agitator (set the operating temperature as $25^{\circ} \mathrm{C}$ during the experiment). The upper clear solution was filtered after stirring for $0 \mathrm{~min}, 20 \mathrm{~min}, 40 \mathrm{~min}, 60 \mathrm{~min}$, $90 \mathrm{~min}$, and $120 \mathrm{~min}$, respectively, then the absorbance of the filtrate was measured by $201 \mathrm{UV}$ spectrophotometer (The test wavelength of the ultraviolet spectrophotometer ranged from 190 to $1100 \mathrm{~nm}$ and the wavelength accuracy was $\pm 0.8 \mathrm{~nm}$ ).

3. Adsorptive capacity calculation

The absorbance peak of SDBS occurs at about $223 \mathrm{~nm}$, and when the solution concentration is 3-5 $\mathrm{mmol} / \mathrm{L}$, the absorbance peak has a good linear relationship with the concentration of SDBS 5 :

$$
C=4.80071 A+0.4465
$$

where, $C$ is concentration of SDBS, $\mathrm{mmol} / \mathrm{L} ; A$ represents the peak wavelength of absorbance.

According to the absorbance test results of filtered filtrate, in combination with formula (1), the adsorptive capacity can be calculated as follows:

$$
q_{t}=\frac{\left(C_{0}-C_{t}\right) V}{m}
$$

where, $q_{\mathrm{t}}$ is the adsorptive capacity at time $t, \mathrm{mmol} / \mathrm{g} ; C_{0}$ represents the initial concentration, $\mathrm{mmol} / \mathrm{L}$; $C_{\mathrm{t}}$ is the concentration at time $t, \mathrm{mmol} / \mathrm{L} ; V$ is the volume of the solution, $\mathrm{L} ; m$ is the mass of the kaolinite, $g$.

(2) Determination of the adsorptive behaviour of kaolinite to SDBS

The adsorptive behaviour of kaolinite to SDBS was investigated mainly by comparing the adsorption process with the classical adsorption kinetic model.

Wherein, the fitting formula of pseudo-first-order adsorption dynamics equation to characterise physical adsorption is as follows ${ }^{5}$ :

$$
q_{t}=q_{e}\left[1-\exp \left(-k_{1} t\right)\right]
$$

where, $q_{\mathrm{e}}$ is the equilibrium absorption capacity, $\mathrm{mmol} / \mathrm{g}$; $k_{1}$ is the first-order adsorption constant, $\mathrm{min}^{-1}$. 
The fitting formula of pseudo-second-order kinetic model to characterise chemical adsorption is as follows ${ }^{5}$ :

$$
q_{\mathrm{t}}=k_{2} q_{e}^{2} t /\left(1-k_{2} q_{e} t\right)
$$

where, $k_{2}$ is the second-order adsorption constant, $\mathrm{g} \cdot \mathrm{mmol}^{-1} \cdot \mathrm{min}^{-1} ; k_{2} q_{\mathrm{e}}^{2}$ is the initial adsorption time, $\mathrm{mmol} \cdot \mathrm{g}^{-1} \cdot \mathrm{min}^{-1}$.

The structural variation of kaolinite before and after adsorption. Centrifuge the mixture of kaolinite and different concentrations SDBS solutions after adsorption, and dry the precipitate in a thermostatic drying chamber. Together with the original kaolinite, respectively, marked as the Original sample, $3 \mathrm{mmol} / \mathrm{L}$ SDBS after adsorption, $4 \mathrm{mmol} / \mathrm{L}$ SDBS after adsorption, $5 \mathrm{mmol} / \mathrm{L}$ SDBS after adsorption, and in preparation for the experiment.

(1) SEM-EDS testing before and after adsorption

The surface morphology of kaolinite before and after adsorption of SDBS were studied by using the SEM-EDS, which was from Carl Zeiss AG, Germany. The experiment was carried out in Henan Polytechnic University. The acceleration voltage of the experiment was $0.2-30 \mathrm{kV}$, and the apparatus able to analyse elements from Be to U. The specific methods are as follows:

1. Gold plating for the four kaolinite samples before and after adsorption.

2. Observe the four gold-plated samples under SEM with different magnifications, and assay the element content by EDS.

3. Analyse the changes of surface morphology and element content before and after adsorption.

(2) XRD testing before and after adsorption

XRD was used to test the variations of surface structure and crystallinity index of kaolinite before and after adsorption of SDBS. The experiment was carried out in Henan Polytechnic University using D8 X-ray diffractometer manufactured by BRUKER-AXS, Germany. The light source adopts X-ray phototube copper target radiation $(\mathrm{Cu}, \lambda 1.5406 \mathrm{~A})$. The divergent slit, anti-scatter slit, Sola slit, and receiving slit were $1.0 \mathrm{~mm}$, $1.0 \mathrm{~mm}, 2^{\circ}$, and $0.2 \mathrm{~mm}$, respectively. The Angle measurement range of this experiment is $2^{\circ} \sim 90^{\circ}$ and the scanning mode was step-scan with a step length and scanning speed of $0.1^{\circ}$ and $3 \mathrm{~s} / \mathrm{step}$. The specific testing process is as follows:

1. Grind the four samples to less than 200 mesh and place them into the test tray for compaction.

2. Test the four samples by XRD, and compare the difference before and after adsorption.

3. Calculate the layer spacing

According to the Bragg Equation ${ }^{25}$ and the 001 peak position $\theta_{001}$, the layer spacing $d_{001}$ can be can be calculated by the following formula:

$$
d_{001}=\frac{\lambda}{2 \sin \theta_{001}}
$$

4. Calculate the crystallinity indices

The crystallinity indices $H_{\mathrm{i}}$ can be calculate from XRD data ${ }^{26}$ :

$$
H_{i}=\frac{A+B}{A_{t}}
$$

where, A and B are the heights of two adjacent diffraction reflections, and At is the distance between the highest reflection of the two adjacent diffraction reflections and the back bottom line.

(3) FTIR testing before and after adsorption

FTIR was used to test the functional group changes of kaolinite before and after adsorption of SDBS. The experiment was carried out in Henan Polytechnic University using 70 FTIR manufactured by BRUKER VERTEX, Germany. The measurement ranges of spectral area, step-scan time resolution, and resolution were 4000 to $400 \mathrm{~cm}^{-1}, 5 \mathrm{~ns}$, and $0.4 \mathrm{~cm}^{-1}$, respectively. The specific method is as follows:

1. Weigh $0.010 \mathrm{~g}$ of the four kaolinite samples, and mix them with $1.500 \mathrm{~g} \mathrm{KBr}$ in a ratio of $1: 150$, respectively.

2. Grind them using an agate mortar until the sample particles were less than 200 mesh equivalent spherical diameter, then place into the thermostatic drying chamber at $80^{\circ} \mathrm{C}$ for $24 \mathrm{~h}$.

3. Grind the dry mixed powder in an agate mortar for 1-2 min, and form tablets for infrared spectroscopy.

\section{Experimental results}

Analyses on the adsorptive behaviour of kaolinite to SDBS. The adsorptive capacity of kaolinite to SDBS was calculated according to the experimental design, and the results are shown in Fig. 1.

In Fig. 1, the adsorptive capacity increased with concentration, and the adsorptive capacity of kaolinite to SDBS with three different concentrations increased slowly over time. 


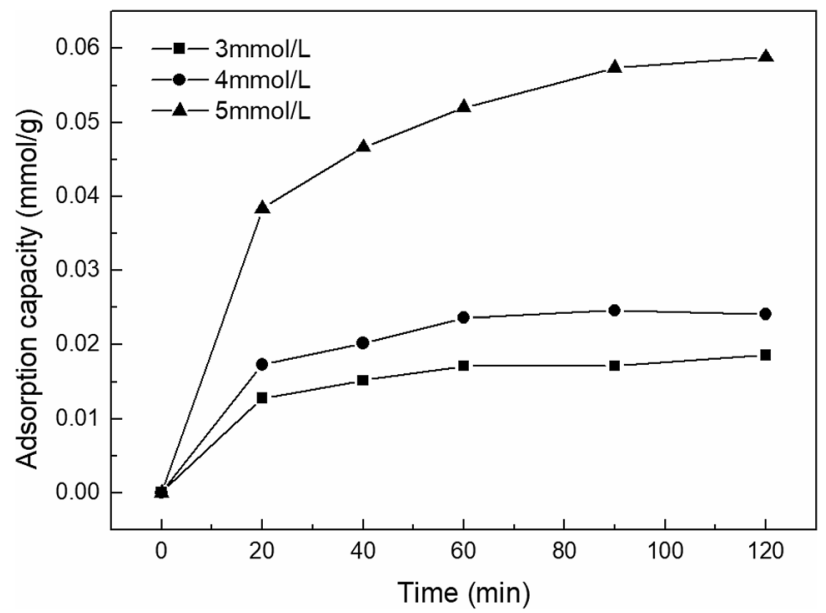

Figure 1. Adsorptive capacity of SDBS on kaolinite at various SDBS concentration under different adsorption time.

\begin{tabular}{|l|l|l|l|l|}
\hline Concentration of SDBS & The pseudo-first order model & $\boldsymbol{q}_{\mathrm{e}}(\exp ) / \mathbf{m m o l} / \mathbf{g}$ & $\boldsymbol{q}_{\mathrm{e}}(\mathbf{c a l}) / \mathbf{m m o l} / \mathbf{g}$ & $\boldsymbol{k}_{\mathbf{1}} / \mathbf{m i n}^{-1}$ \\
\hline $3 \mathrm{mmol} / \mathrm{L}$ & $q_{\mathrm{t}}=0.01772 \times\left(1-\mathrm{e}^{-0.05844 \times \mathrm{t}}\right)$ & 0.0186 & 0.0177 & 0.058 \\
\hline $4 \mathrm{mmol} / \mathrm{L}$ & $q_{\mathrm{t}}=0.02416 \times\left(1-\mathrm{e}^{-0.05714 \times t}\right)$ & 0.0246 & 0.0241 & 0.057 \\
\hline $5 \mathrm{mmol} / \mathrm{L}$ & $q_{\mathrm{t}}=0.05722 \times\left(1-\mathrm{e}^{-0.04906 \times t}\right)$ & 0.0588 & 0.0572 & 0.049 \\
\hline Concentration of SDBS & The pseudo-second order model & $\boldsymbol{q}_{\mathrm{e}}(\mathbf{e x p}) / \mathbf{m m o l} / \mathbf{g}$ & $\boldsymbol{q}_{\mathrm{e}}(\mathbf{c a l}) / \mathbf{m m o l} / \mathbf{g}$ & $\boldsymbol{k}_{2} / \mathbf{m m o l} \cdot \mathbf{g}^{-1} \cdot \mathbf{m i n}^{-1}$ \\
\hline $3 \mathrm{mmol} / \mathrm{L}$ & $q_{\mathrm{t}}=\mathrm{t} /(582.6025+50 \times \mathrm{t})$ & 0.0186 & 0.0182 & 4.291 \\
\hline $4 \mathrm{mmol} / \mathrm{L}$ & $q_{\mathrm{t}}=\mathrm{t} /(430.3774+36.75119 \times \mathrm{t})$ & 0.0246 & 0.0241 & 3.138 \\
\hline $5 \mathrm{mmol} / \mathrm{L}$ & $q_{\mathrm{t}}=\mathrm{t} /(231.368+15.11944 \times \mathrm{t})$ & 0.0588 & 0.0587 & 0.988 \\
\hline
\end{tabular}

Table 2. Fitting results of pseudo-first order and pseudo-second order model at different concentrations.

According to formulae (3) and (4), different models were used to fit the experimental process. The fitting results and main adsorption parameters are listed in Table 2.

A variety of error analysis method, including the root mean square error (RMSE), chi-squared distribution $\left(\chi^{2}\right)$, G party inspection $\left(G^{2}\right)$, error sum of squares (ERRSQ), composite relative error function (HYBRZD), Marquardt proportion standard deviation derivative (MPSD), average relative deviation (ARE), sum of absolute error (EABS), absolute pose error (APE), Akaike information criterion (AIC), Mallows $C_{\mathrm{p}}$ (Mallows), etc., were used in the discussion of the correlation of fitting (Table 3).

From the calculated results of various error functions in Tables 1 and 2, the pseudo-secondary adsorption kinetic model returned a smaller error and was more consistent with the adsorption performance, indicating that the adsorption on the kaolinite surface of SDBS is mainly chemical. The adsorption constant decreases gradually with the increased concentration of SDBS, this is mainly because the repulsion between adsorbed molecules and free SDBS molecules in solution increases with the increase of SDBS concentration.

The structural variation of kaolinite before, and after, adsorption. Surface morphology variation characteristics of kaolinite before, and after, adsorption. SEM scanning results for part of the samples before and after the adsorption of SDBS by kaolinite are shown in Fig. 2, and the EDS test results are shown in Figs. 3, 4, 5.

Figure 2 shows that the structure of kaolinite layers after adsorption of SDBS is clearer, and the phenomenon of plate formation is more obvious. As can be seen from Figs. 3, 4, 5: O, Al, and Si are the main elements found on the surface of the kaolinite, while a small amount of C mainly originates from the SEM sample holder or some carbonate impurities thereon. According to the results of energy spectral analysis, the content of element $\mathrm{O}$ is higher, $\mathrm{Al}$ and $\mathrm{Si}$ have little difference in their contents. It is believed that the unit structure of kaolinite is composed of a layer of silicon-oxygen tetrahedron and a layer of aluminium-oxygen octahedron, with a high crystallinity therein ${ }^{27,28}$, which meets the experimental requirements.

Characteristics of interlayer change before, and after, kaolinite adsorption. The interlayer change before and after kaolinite adsorption is shown in Fig. 6.

According to the XRD test results of kaolinite under the original conditions and after absorbing SDBS of different concentrations (Fig. 6), it can be found that no new characteristic reflections were generated for kaolinite before and after adsorption. The $2 \theta$ of 001 reflection for kaolinite samples in the original state and after 


\begin{tabular}{|c|c|c|c|c|c|c|}
\hline \multirow[b]{2}{*}{ Error Function Model } & \multicolumn{3}{|c|}{ Pseudo-first order kinetic model } & \multicolumn{3}{|c|}{$\begin{array}{l}\text { Pseudo-second order adsorption } \\
\text { model }\end{array}$} \\
\hline & $3 \mathrm{mmol} / \mathrm{L}$ & $4 \mathrm{mmol} / \mathrm{L}$ & $5 \mathrm{mmol} / \mathrm{L}$ & $3 \mathrm{mmol} / \mathrm{L}$ & $4 \mathrm{mmol} / \mathrm{L}$ & $5 \mathrm{mmol} / \mathrm{L}$ \\
\hline $\operatorname{RMSE}\left(10^{-3}\right)$ & 0.71 & 0.91 & 2.34 & 0.42 & 0.74 & 0.93 \\
\hline$\chi^{2}\left(10^{-4}\right)$ & 1.25 & 1.62 & 4.76 & 0.42 & 0.96 & 0.73 \\
\hline $\mathrm{G}^{2}\left(10^{-4}\right)$ & 3.00 & 4.50 & 15.44 & 0.81 & 0.69 & 2.41 \\
\hline ERRSQ $\left(10^{-6}\right)$ & 2.01 & 3.32 & 21.82 & 0.72 & 2.18 & 3.44 \\
\hline $\operatorname{HYBRD}\left(10^{-4}\right)$ & 1.25 & 1.67 & 4.72 & 0.42 & 0.97 & 0.73 \\
\hline $\operatorname{MPSD}\left(10^{-3}\right)$ & 7.88 & 8.45 & 10.44 & 2.49 & 4.33 & 1.60 \\
\hline ARE & 0.17 & 0.16 & 0.21 & 0.11 & 0.13 & 0.07 \\
\hline EABS $\left(10^{-3}\right)$ & 2.80 & 3.18 & 9.95 & 1.75 & 3.02 & 3.80 \\
\hline APE\% & 3.52 & 3.14 & 4.18 & 2.10 & 2.69 & 1.59 \\
\hline $\mathrm{AIC}_{\mathrm{C}}$ & -81.46 & -78.46 & -67.15 & -87.65 & -80.97 & -78.25 \\
\hline Mallows $\left(10^{-3}\right)$ & 2.83 & 3.63 & 9.34 & 1.69 & 2.95 & 3.70 \\
\hline
\end{tabular}

Table 3. Error analysis of the fitting results of kaolinite adsorption kinetics under different SDBS concentrations.
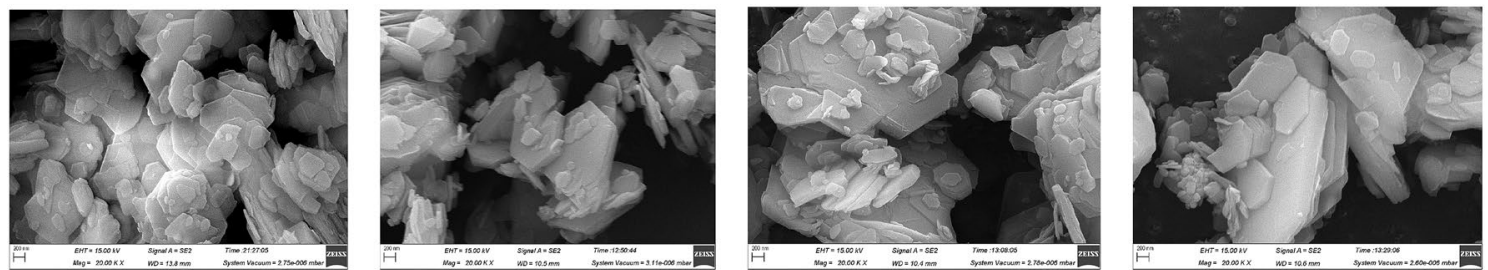

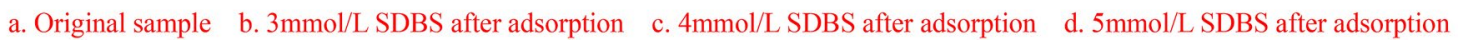

Figure 2. SEM test chart before and after the adsorption of kaolinite, (a) Original sample (b) $3 \mathrm{mmol} / \mathrm{L}$ SDBS after adsorption (c) $4 \mathrm{mmol} / \mathrm{L}$ SDBS after adsorption (d) $5 \mathrm{mmol} / \mathrm{L}$ SDBS after adsorption.
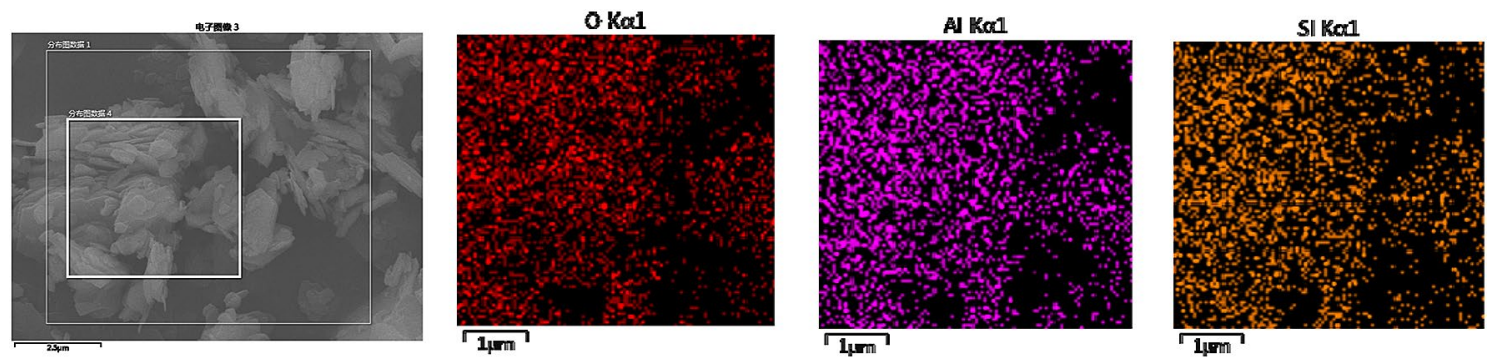

Figure 3. EDS scan of samples before adsorption of kaolinite.
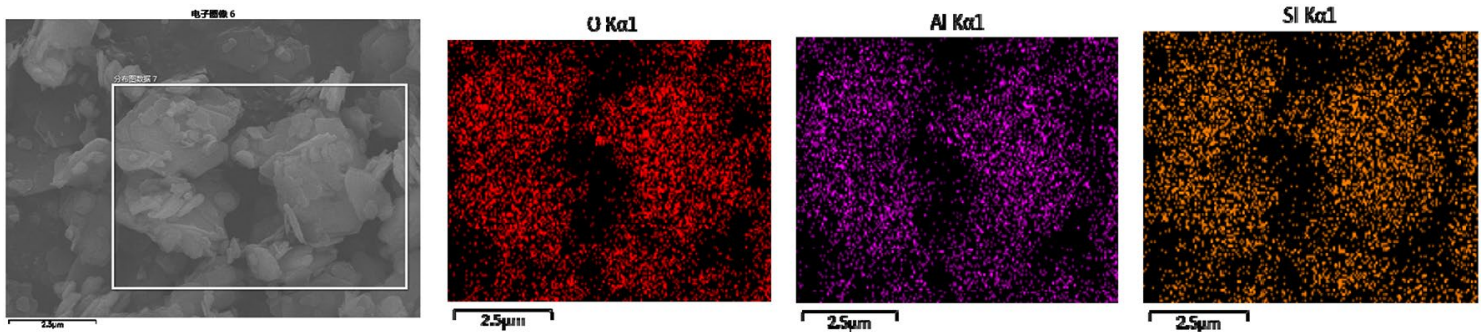

Figure 4. EDS scan of kaolinite after the adsorption of $4 \mathrm{mmol} / \mathrm{L}$ SDBS.

absorbing $3 \mathrm{mmol} / \mathrm{L}, 4 \mathrm{mmol} / \mathrm{L}$, and $5 \mathrm{mmol} / \mathrm{L}$ SDBS are basically consistent, indicating that the kaolinite layer spacing D001 crystallinity indices did not change significantly. The SDBS was hardly adsorbed between layers of kaolinite, and the adsorption mainly occurred on the surface.

According to Formula (6), the crystallinity indices of kaolinite under the original state and after absorbing different concentrations of SDBS is calculated (Fig. 7). The required parameters and calculation results are shown 

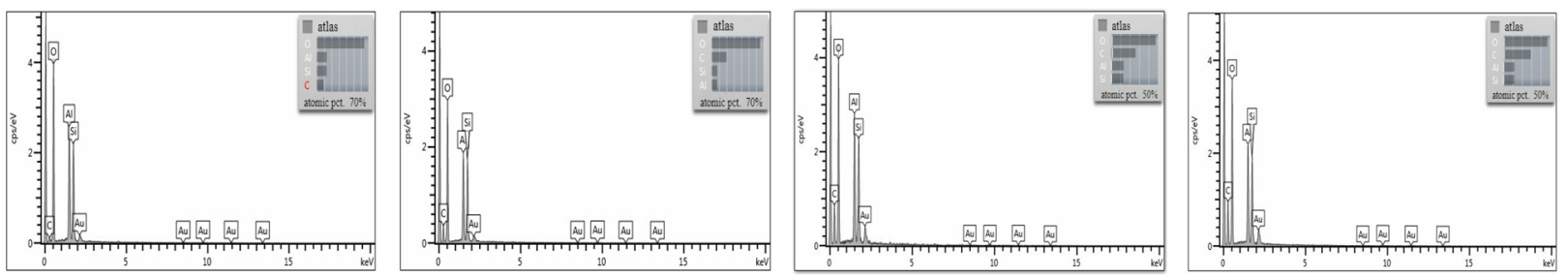

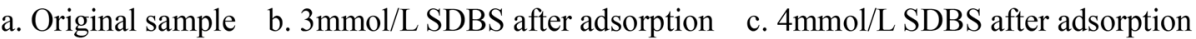

d. $5 \mathrm{mmol} / \mathrm{L}$ SDBS after adsorption

Figure 5. EDS scan of kaolinite before and after adsorption. (a) Original sample (b) $3 \mathrm{mmol} / \mathrm{L}$ SDBS after adsorption (c) $4 \mathrm{mmol} / \mathrm{L}$ SDBS after adsorption (d) $5 \mathrm{mmol} / \mathrm{L}$ SDBS after adsorption.

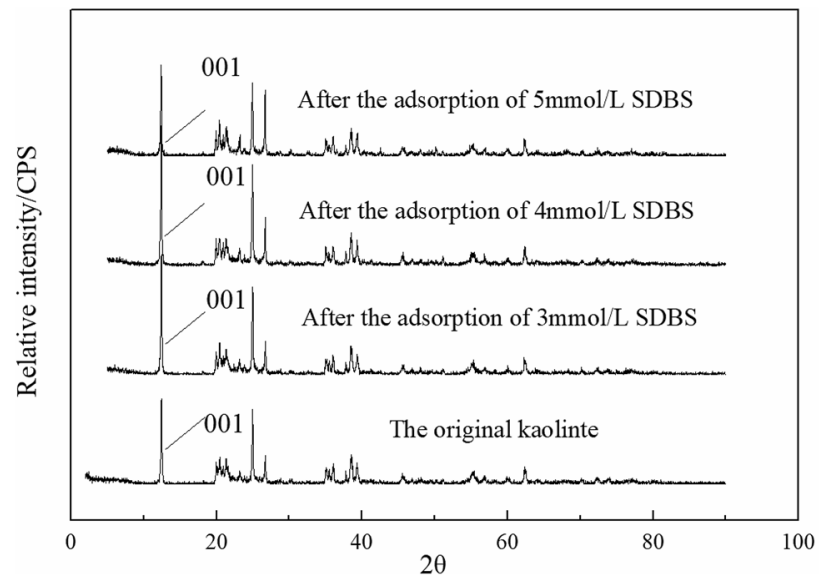

Figure 6. Comparison of XRD test results.

in Table 4. The results shows that after the adsorption of SDBS, the crystallinity indices of kaolinite increased significantly, and when the SDBS concentration was $4 \mathrm{mmol} / \mathrm{L}$, the crystallinity indices reached the maximum, which is consistent with the SEM observation results.

Changes in major functional groups before, and after, kaolinite adsorption. According to the experimental method ("Research methods"), the infrared spectrum testing results of kaolinite before and after adsorption were obtained (Fig. 8).

The infrared spectrum test results of kaolinite under the original conditions and after absorbing SDBS of different concentrations were compared (Fig. 8). It is found that after absorbing SDBS on kaolinite, the bending vibration peaks of $-\mathrm{CH}_{3}$ and $-\mathrm{CH}_{2}-$ appeared at $1475-1350 \mathrm{~cm}^{-1}$ indicating that kaolinite has adsorbed SDBS. The intensity ratio of $\mathrm{vSO}_{3}^{-}$at $2370 \mathrm{~cm}^{-1}$ increased significantly, which also proved the existence of adsorption phenomenon. The intensity ratio of the internal hydroxyl at $3620 \mathrm{~cm}^{-1}$ and the external hydroxyl at $3690 \mathrm{~cm}^{-1}$ was significantly weakened, and with the increase of SDBS concentration, the weakening was more obvious, which indicates that chemical combination occurred between SDBS and the hydroxyl of the kaolinite. The significant decrease of $v \mathrm{SiO}$ at $1107 \mathrm{~cm}^{-1}$ and that of $\delta(\mathrm{Al}-) \mathrm{OH}$ at $914 \mathrm{~cm}^{-1}$ suggested that chemical adsorption occurred between SDBS and Si and Al. The intensity ratio of $1000-1008 \mathrm{~cm}^{-1}$ bands of the tetrahedral layer changed significantly, indicating the change of the chemical environment after kaolinite adsorbed SDBS.

\section{Conclusion}

(1) The linear relationship between absorbance and concentration-absorbance measured by spectrophotometer was used to calculate the adsorptive capacity and adsorptive behaviour of SDBS on the surface of kaolinite at different concentrations $(3 \mathrm{mmol} / \mathrm{L}, 4 \mathrm{mmol} / \mathrm{L}$, and $5 \mathrm{mmol} / \mathrm{L})$ at different times. The results showed that the higher the SDBS concentration, the higher the adsorptive capacity, but the higher the concentration, the lower the initial adsorption rate. Its adsorption is best described by the pseudo-secondary adsorption kinetics model, suggesting mainly chemical adsorption. 


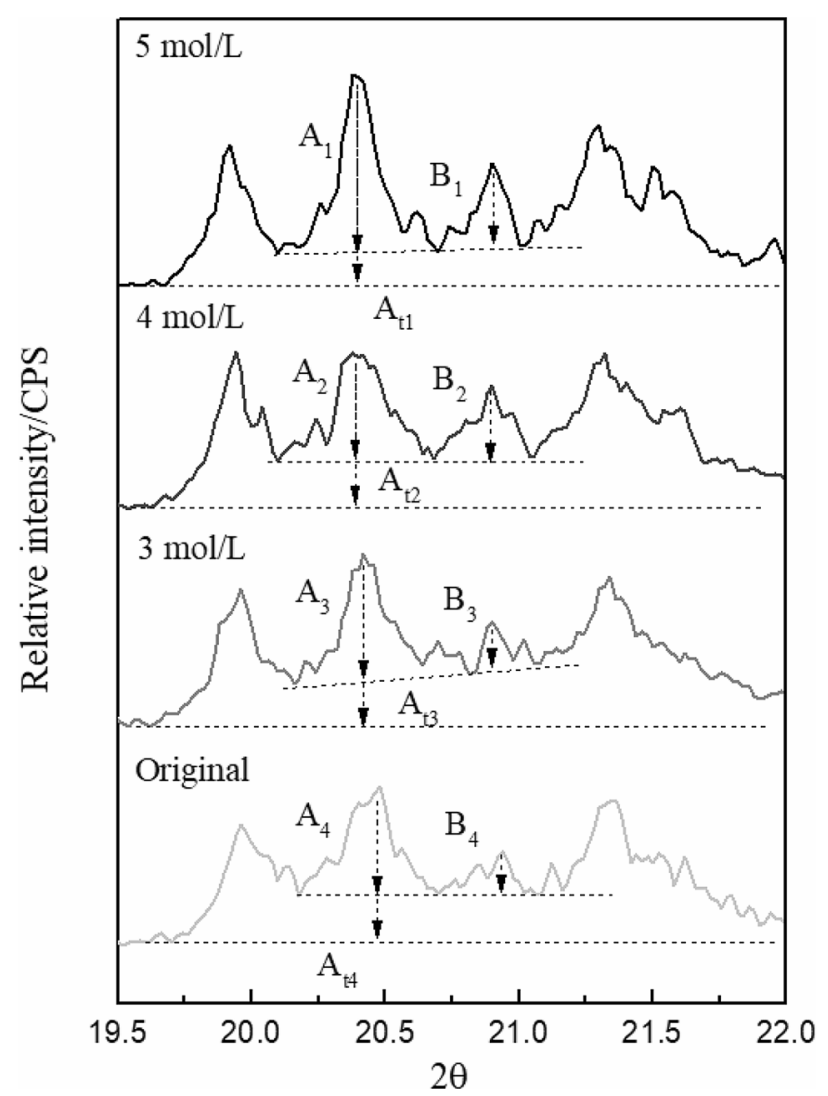

Figure 7. Calculation of crystallinity indices of kaolinite.

\begin{tabular}{|l|l|l|l|l|}
\hline Sample & A & $\mathbf{B}$ & $\mathbf{A}_{\mathbf{t}}$ & $\mathbf{H}_{\mathbf{i}}$ \\
\hline Original sample & 51.0 & 21.0 & 74.0 & 1.06 \\
\hline $3 \mathrm{mmol} / \mathrm{L}$ SDBS after adsorption & 67.5 & 27.0 & 87.0 & 1.09 \\
\hline $4 \mathrm{mmol} / \mathrm{L}$ SDBS after adsorption & 54.5 & 42.5 & 73.0 & 1.33 \\
\hline $5 \mathrm{mmol} / \mathrm{L}$ SDBS after adsorption & 83.0 & 41.5 & 99.0 & 1.26 \\
\hline
\end{tabular}

Table 4. The required parameters and calculation results of crystallinity indices.

(2) The results of SEM-EDS, XRD, and FTIR show that SDBS was mainly adsorbed on the surface of kaolinite. After the adsorption of SDBS, the solidification and lamellar aggregation of kaolinite were more obvious, the crystallinity index of kaolinite increased significantly, and the crystallinity index reached the maximum when the SDBS concentration was $4 \mathrm{mmol} / \mathrm{L}$. In addition, the intensity ratio of $1000-1008 \mathrm{~cm}^{-1}$ bands of the tetrahedral layer changed significantly, indicating that the adsorptive behaviour was chemical.

(3) The adsorption behaviours of kaolinite mineral to SDBS with different concentrations were identified, however, rock contains kaolinite, montmorillonite, illite, and other clay minerals; mineral concentration, formation temperature, formation water $\mathrm{pH}$, and composition are likely to affect the adsorption behaviour of SDBS. Future work should focus on analysis of the clay under different environments and the adsorption mechanisms of dodecyl benzene sulphonic acid sodium. 


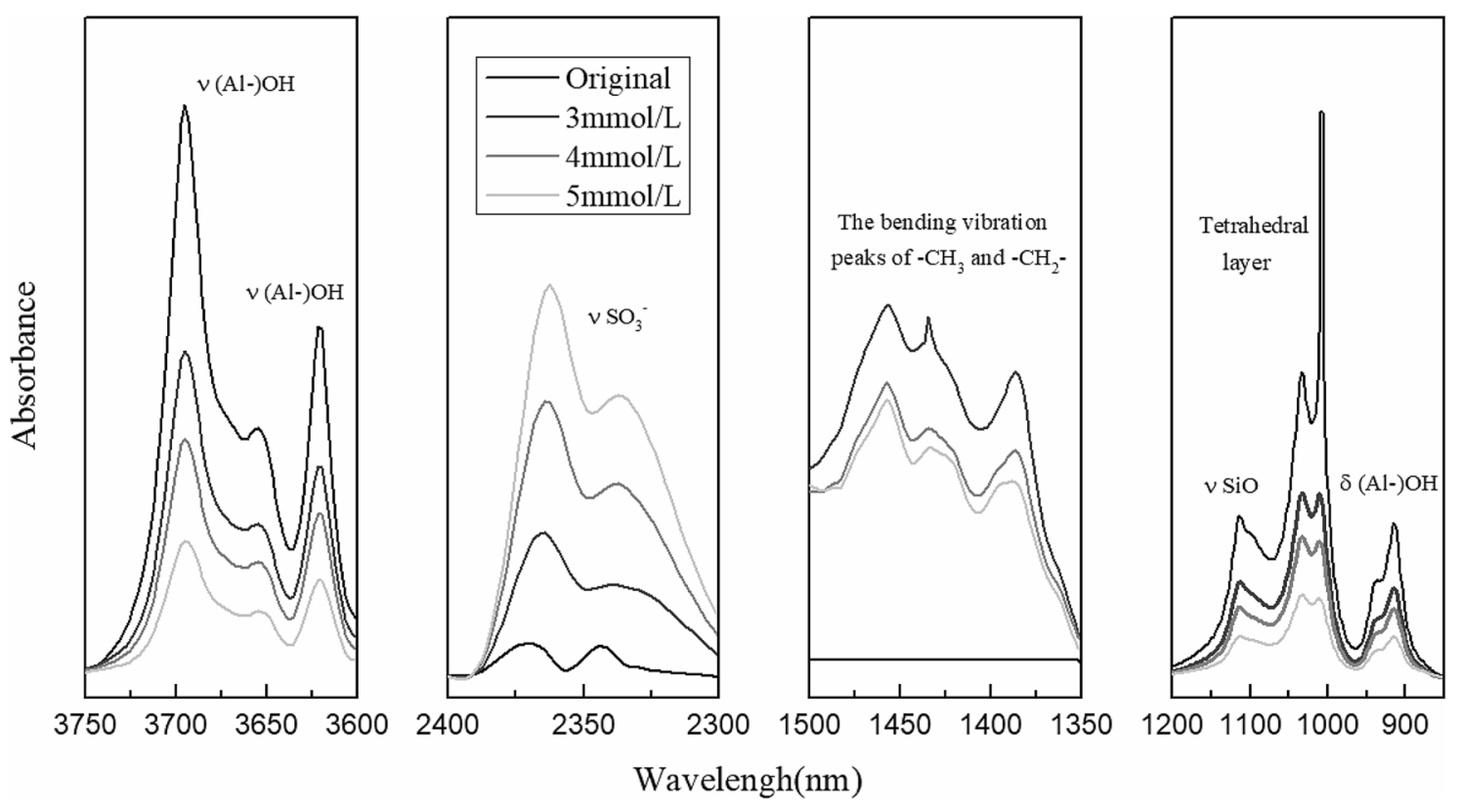

Figure 8. Infrared spectrum testing results under different concentration of concentration solution.

\section{Data availability}

The data used to support the findings of this study are included within the article.

Received: 18 March 2020; Accepted: 30 December 2020

Published online: 19 January 2021

\section{References}

1. Mohamed, S. et al. Adsorption behavior of inorganic- and organic-modified kaolinite for Congo red dye from water, kinetic modeling, and equilibrium studies. J. Sol-Gel. Sci. Technol. 87(2), 427-441 (2018).

2. Abukhadra, M. R. et al. Facile conversion of kaolinite into clay nanotubes (KNTs) of enhanced adsorption properties for toxic heavy metals $\left(\mathrm{Zn}^{2+}, \mathrm{Cd}^{2+}, \mathrm{Pb}^{2+}\right.$, and $\left.\mathrm{Cr}^{6+}\right)$ from water. J. Hazard. Mater. 374, 296-308 (2019).

3. Xin, K. et al. Effects of inorganic cations and organic polymers on the physicochemical properties and microfabrics of kaolinite suspensions. Appl. Clay Sci. 176, 38-48 (2019).

4. Xin, K. et al. Effects of inorganic ions, organic polymers, and fly ashes on the sedimentation characteristics of kaolinite suspensions. Appl. Clay Sci. 181, 2 (2019).

5. Ni, X. M., Li, Z. H. \& Wang, Y. B. Adsorption characteristics of anionic surfactant sodium dodecylbenzene sulfonate on the surface of montmorillonite minerals. Front. Chem. 6, 390 (2018).

6. Yang, Y., Guo, C. H. \& Luo, T. T. The adsorption properties of viscoelastic surfactant on coal powder. J. China Coal Soc. 36(01), $110-113(2011)$.

7. Zhang, W. C. \& You, L. J. Test on the adsorption performance of fluorocarbon surfactant on rock mineral surface. J. Yangtze Univ. Nat. Sci. Ed. 13(28), 6-12 (2016).

8. Ma, A. J., He, R. H. \& Zhou, L. X. Behavior and mechanism of napropamide adsorption in soil-water environment. Acta Sci. Circum. 07, 1159-1163 (2006).

9. Xu, L. H. et al. Absorption characteristics of quaternary ammonium on kaolinite. J. Central South Univ. Sci. Technol. 44(11), 4379-4384 (2013).

10. Arami, M., Limaee, N. Y. \& Mahmoodi, N. M. Evaluation of the adsorption kinetics and equilibrium for the potential removal of acid dyes using a biosorbent. Chem. Eng. J. 139(1), 2-10 (2008).

11. Chang, Q., Lin, W. \& Ying, W. C. Impacts of amount of impregnated iron in granular activated carbon on arsenate adsorption capacities and kinetics. Water Environ. Res. 84(6), 514-520 (2012).

12. Guo, L. et al. Nonlinear analysis of the kinetics and equilibrium for adsorptive removal of Cd(II) by starch phosphate. J. Dispersion Sci. Technol. 33(3), 403-409 (2012).

13. Imran, D. M. et al. Thermodynamics of biosorption for removal of Co(II) ions by an efficient and ecofriendly biosorbent (Saccharum bengalense): Kinetics and isotherm modeling. J. Chem. 2013, 1-11 (2013).

14. Mi, X. et al. Enhanced adsorption of orange II using cationic surfactant modified biochar pyrolyzed from cornstalk. J. Chem. 2016, 1-7 (2016).

15. Abukhadra, M. R., El-Meligy, M. A. \& El-Sherbeeny, A. M. Evaluation and characterization of Egyptian ferruginous kaolinite as adsorbent and heterogeneous catalyst for effective removal of safranin-O cationic dye from water. Arab. J. Geosci. 13(4), 169 (2020).

16. Wu, F. C. et al. Characteristics of pseudo-second-order kinetic model for liquid-phase adsorption: A mini-review. Chem. Eng. J. 151(1-3), 1-9 (2009).

17. Largitte, L. \& Pasquier, R. New models for kinetics and equilibrium homogeneous adsorption. Chem. Eng. Res. Des. 112, 289-297 (2016).

18. Fatimah, I. Preparation, characterization and physicochemical study of 3-amino propyl trimethoxy silane-modified kaolinite for $\mathrm{Pb}(\mathrm{II})$ adsorption. J. King Saud Univ. Sci. 30(2), 250-257 (2018).

19. Atkin, R. et al. Mechanism of mechanism of cationic surfactant adsorption at the solid-aqueous interface. Adv. Coll. Interface. Sci. 103(3), 219-304 (2003).

20. Li, H. P. et al. Mechanism of interaction between cationic surfactant and kaolinite. J. Central South Univ. Sci. Technol. 35(2), 228-233 (2004). 
21. Zhou, J. B., Wu, P. X. \& Zhu, N. W. Adsorption of $\mathrm{Cu}^{2+}$ and $\mathrm{Cd}^{2+}$ by SDS-modified montmorillonite. Acta Sci. Circum. 30(1), 88-96 (2010).

22. Liu, Q. F. et al. Preparation and structural characterization of kaolinite intercalation compounds with series of quaternary ammonium salt. J. Chin. Ceram. Soc. 43(02), 222-230 (2015).

23. Xue, R. et al. Molecular dynamics simulation of the wettability of kaolinite and illite. Geol. J. China Univ. 21(4), 594-602 (2015).

24. Jawed, A. \& Pandey, L. M. Application of bimetallic Al-doped $\mathrm{ZnO}$ nano-assembly for heavy metal removal and decontamination of wastewater. Water Sci. Technol. 80(11), 2067-2078 (2019).

25. Korotchenko, K. B. \& Kunashenko, Y. P. Quantum theory of X-ray radiation at Bragg angles at channeling. Radiat. Phys. Chem. 109, 83-88 (2015).

26. Hinckley, D. N. Variability in "Crystallinity" values among the kaolin deposits of the coastal plain of Georgia and South Carolina. Clays Clay Miner. 11(1), 229-235 (1963).

27. Park, Y., Ayoko, G. A. \& Frost, R. L. Characterisation of organoclays and adsorption of p-nitrophenol: Environmental application. J. Colloid Interface Sci. 360(2), 440-456 (2011).

28. Liu, J. et al. Surface force measurements at kaolinite edge surfaces using atomic force microscopy. J. Colloid Interface Sci. 420, $35-40$ (2014).

\section{Acknowledgments}

This study was supported by the National Science and Technology Major Projects of China (2017ZX05064-002), the National Natural Science Foundation of China (41872174), the Program for Innovative Research Team in University of Ministry of Education of China (IRT_16R22) and the Central Plains Economic Zone of coal seam gas (Ye Yan) Henan Collaborative Innovation Center.

\section{Author contributions}

X.N.: conceptualization, methodology, writing-original draft preparation. Z.Z.: writing-reviewing and editing, experimentation. Z.L.: conceptualization, experimentation. Q.L.: visualization, supervision.

\section{Competing interests}

The authors declare no competing interests.

\section{Additional information}

Correspondence and requests for materials should be addressed to Z.Z.

Reprints and permissions information is available at www.nature.com/reprints.

Publisher's note Springer Nature remains neutral with regard to jurisdictional claims in published maps and institutional affiliations.

(c) (i) Open Access This article is licensed under a Creative Commons Attribution 4.0 International License, which permits use, sharing, adaptation, distribution and reproduction in any medium or format, as long as you give appropriate credit to the original author(s) and the source, provide a link to the Creative Commons licence, and indicate if changes were made. The images or other third party material in this article are included in the article's Creative Commons licence, unless indicated otherwise in a credit line to the material. If material is not included in the article's Creative Commons licence and your intended use is not permitted by statutory regulation or exceeds the permitted use, you will need to obtain permission directly from the copyright holder. To view a copy of this licence, visit http://creativecommons.org/licenses/by/4.0/.

(C) The Author(s) 2021 